\title{
Serum squamous cell carcinoma antigen is a predictive factor of outcomes in patients with locally advanced unresectable esophageal squamous cell carcinoma treated by definitive chemoradiotherapy
}

Takeshi Suzuki ${ }^{1}$, Akihiko Okamura ${ }^{2}$, Masayuki Watanabe ${ }^{2}$, Takao Asari ${ }^{3}$, Izuma Nakayama', Mariko Ogura', Akira Ooki', Daisuke Takahari', Kensei Yamaguchi', Keisho Chin ${ }^{1}$

\begin{abstract}
'Department of Gastroenterological Medicine, Cancer Institute Hospital of the Japanese Foundation for Cancer Research, Kotoku, Tokyo 135-8550, Japan.

${ }^{2}$ Department of Gastroenterological Surgery, Cancer Institute Hospital of the Japanese Foundation for Cancer Research, Koto-ku, Tokyo 135-8550, Japan.

${ }^{3}$ Department of Radiation Oncology, Cancer Institute Hospital of the Japanese Foundation for Cancer Research, Koto-ku, Tokyo 135-8550, Japan.
\end{abstract}

Correspondence to: Dr. Akihiko Okamura, Department of Gastroenterological Surgery, Cancer Institute Hospital of the Japanese Foundation for Cancer Research, 3-8-31 Ariake, Koto-ku, Tokyo 135-8550, Japan. E-mail: akihiko.okamura@jfcr.or.jp

How to cite this article: Suzuki T, Okamura A, Watanabe M, Asari T, Nakayama I, Ogura M, Ooki A, Takahari D, Yamaguchi K, Chin K. Serum squamous cell carcinoma antigen is a predictive factor of outcomes in patients with locally advanced unresectable esophageal squamous cell carcinoma treated by definitive chemoradiotherapy. J Cancer Metastasis Treat 2022;8:5.

https://dx.doi.org/10.20517/2394-4722.2021.160

Received: 8 Aug 2021 First Decision: 30 Sep 2021 Revised: 4 Oct 2021 Accepted: 14 Jan 2022 Published: 25 Jan 2022

Academic Editors: Lucio Miele, Jan Baptist Vermorken, Guofeng Xie Copy Editor: Yue-Yue Zhang Production Editor: Yue-Yue Zhang

\begin{abstract}
Aim: Definitive chemoradiotherapy (dCRT) is the standard treatment for locally advanced unresectable esophageal squamous cell carcinoma (LU-ESCC). This study aimed to describe the results of dCRT for T4 ESCC and evaluate the pretherapeutic predictive factors of the outcomes.

Methods: A total of 133 patients with T4 ESCC who received dCRT were grouped into those who achieved a complete response (CR) or those who had residual disease (RD). The clinicopathologic variables were compared between the groups and the overall survival (OS) was evaluated. The predictive factor of RD was assessed and the prognostic factor for OS was identified.
\end{abstract}


Results: Among the 133 patients, 31 (23\%) achieved CR. The CR group had a significantly better OS than the RD group (89.9 months vs. 10.7 months; hazard ratio $=0.096 ; 95 \%$ confidence interval: 0.05-0.19; $P<0.001$ ). Multivariate analysis showed that a supracarinal tumor ( $O R=3.21 ; P=0.016$ ), higher pretherapeutic serum SCC-Ag level $(>1.6 \mathrm{ng} / \mathrm{mL})(\mathrm{OR}=2.86 ; P=0.018)$, and metastatic node invasion $(\mathrm{OR}=3.19 ; P=0.048)$ were independent predictors of RD. The increased level of pretherapeutic serum squamous cell carcinoma antigen ( $>$ $1.6 \mathrm{ng} / \mathrm{mL})(\mathrm{OR}=1.61 ; P=0.022)$ was an independent predictor of poor survival.

Conclusions: Among the patients who underwent dCRT for LU-ESCC, 23\% achieved CR, and the long-term outcome of these patients was favorable. Increased levels of pretherapeutic serum squamous cell carcinoma antigen were also found to be predictive of treatment failure.

Keywords: Esophageal cancer, chemoradiotherapy, esophageal squamous cell carcinoma, predictive factor

\section{INTRODUCTION}

Recently updated data by the World Health Organization suggested that esophageal cancer is the eighth leading cause of death worldwide ${ }^{[1]}$. Esophageal squamous cell carcinoma (ESCC), which mostly occurs in Asian countries ${ }^{[2]}$, often invades neighboring organs, including the trachea, bronchus, and aorta ${ }^{[3-5]}$.

Definitive chemoradiotherapy (dCRT) has been the only modality to provide a cure for locally advanced unresectable ESCC (LU-ESCC) without distant metastasis. In Japan, the Esophageal Cancer Practice Guidelines have suggested only weak evidence for recommending radial chemoradiotherapy for treatment of stage IVa esophageal cancer according to the results of several clinical trials ${ }^{[6-9]}$, while dCRT with cisplatin plus fluorouracil (FP) and irradiation has been commonly utilized for these patients.

There exist only a few actual clinical reports that have included a sufficient number of patients receiving dCRT for LU-ESCC ${ }^{[10]}$. Moreover, pretherapeutic predictors for responses and prognosis have not been well-elucidated $^{[10]}$. We had previously reported that pretherapeutic serum squamous cell carcinoma antigen (SCC-Ag) levels were associated with poor response to neoadjuvant treatment and prognosis in patients with ESCC ${ }^{[1,12]}$. However, the predictive value of serum SCC antigen in patients undergoing dCRT remains unknown.

The present study aimed to uncover the actual clinical practice of dCRT for LU-ESCC with relatively large sample size and determine the pretherapeutic predictive factors for treatment response and prognosis among patients with dCRT for LU-ESCC.

\section{METHODS}

\section{Patients and study design}

This retrospective single-center study included 133 patients with LU-ESCC who received dCRT between April 2005 and March 2019 at the Cancer Institute Hospital of Japanese Foundation for Cancer Research. Here, LU-ESCC comprised tumors that directly invaded neighboring vital organs (T4b tumors, primary tumor invasion) and those wherein regional metastatic lymph nodes invaded neighboring organs (non-T4b tumors, metastatic node invasion). Patients with supraclavicular lymph (M1) were included in the analysis; however, those with supraclavicular lymph node metastasis but without LU-ESCC and those with other distant metastasis were excluded from the analysis. A multidisciplinary tumor board conducted pretreatment evaluation for LU-ESCC mainly according to endoscopy and contrast-enhanced computed tomography (CT) findings. Positron emission tomography, magnetic resonance imaging, and bronchoscopy were performed as needed. 
The included patients were classified into two groups: the complete response (CR) group consisted of patients who achieved CR following treatment, and the residual disease (RD) group consisted of those who had residual cancer lesions even after treatment. In this study, CR was determined using endoscopy and CT findings indicating the absence of both primary tumors and lymph node metastases, although biopsy specimens were not required for confirming negative cancer cells. Moreover, in this study, CR was confirmed when patients underwent no cancer treatment without apparent cancer progression at least 1 year after treatment.

Clinical characteristics and survival rates were compared between both groups, and pretherapeutic clinical factors for $\mathrm{RD}$ and poor prognosis were identified. Our study protocol was reviewed and approved by the ethics committee of the Japanese Foundation for Cancer Research.

\section{Treatment}

dCRT consisted of two courses with FP plus irradiation with 60 Gy. Chemotherapy with FP consisted of continuous fluorouracil infusion at $700 \mathrm{mg} / \mathrm{m}^{2}$ on days $1-4$ and cisplatin at $70 \mathrm{mg} / \mathrm{m}^{2}$ over $2 \mathrm{~h}$ on day 1 for 4 weeks. Radiotherapy was delivered via multiportal beams or intensity-modulated radiation therapy to the planning target volume at a dose of 2 Gy daily, five times per week for 6 weeks. The planning target volume consisted of the primary tumor, regional, and metastatic lymph nodes and an adequate margin. Preventive margin could be omitted if radiation dose to the vital organs was higher than the acceptable amount. When both courses of chemotherapy with FP plus irradiation promoted tumor shrinkage, an additional two courses of chemotherapy with fluorouracil infusion at $800 \mathrm{mg} / \mathrm{m}^{2}$ on days $1-5$ and cisplatin at $80 \mathrm{mg} / \mathrm{m}^{2}$ over 2 h on day 1 for 4 weeks were allowed. Response evaluation for each patient was performed about 1 month after treatment completion. For RD patients and those who experienced recurrence after CR, salvage surgery was considered.

\section{Data collection and definition}

Clinicopathological factors collected from the 133 patients enrolled herein included pretherapeutic age, sex, main tumor location, clinical tumor status, serum SCC-Ag level, and Glasgow prognostic score ${ }^{[13]}$. Tumor stage classification was based on the 8th edition of the Union for International Cancer Control ${ }^{[14]}$. Serum SCC-Ag levels were assessed upon visiting the outpatient clinics and were measured under a chemiluminescent microparticle immunoassay (Abbott Japan Co. Ltd, Tokyo, Japan).

\section{Statistical analysis}

Continuous variables are presented as medians and ranges. Statistical comparisons among groups were conducted using the $t$-test or chi-squared test, while multivariate logistic regression analysis was used to calculate the odds ratio (OR) and 95\% confidence intervals (CIs) for RD. The cutoff serum SCC-Ag level predictive of $\mathrm{RD}$, which was $1.6 \mathrm{ng} / \mathrm{mL}$, was determined using receiver operating characteristic curve analysis. Overall survival (OS) was evaluated from the date of dCRT initiation until death due to any cause or last follow-up. Cumulative survival was estimated using the Kaplan-Meier method, while the Cox proportional hazard regression model was used to elucidate the impact of variables on survival, with results presented as hazard ratios (HRs) and 95\%CIs. Multivariate models using stepwise selection were used for adjusting for pretherapeutic confounders, including age at dCRT, sex (female vs. male), main tumor location (infracarina vs. supracarina), serum SCC-Ag level ( $\leq 1.6 \mathrm{ng} / \mathrm{mL} v s .>1.6 \mathrm{ng} / \mathrm{mL}$ ), Glasgow prognostic score $(0,1$, and 2$)$, clinical $\mathrm{T}$ stage [non-T4b (metastatic node invasion) vs. T4b (primary tumor invasion)], clinical N stage (No-1 vs. N2-3), and clinical M stage (Mo vs. M1). A probability $(P)$ value of < 0.05 was considered statistically significant. All statistical analyses were performed using R Statistics (The R Project for Statistical Computing; https://www.r-project.org) $)^{[15]}$. 


\section{RESULTS}

\section{Patient characteristics and patient flow}

The characteristics of eligible patients are summarized in Table 1. The median age was 63 years, with males accounting for $77 \%(n=103)$ of the patients. Tumors were located at the supracarinal and intracranial esophagus in $56(42 \%)$ and 77 (58\%) patients, respectively. Among the patients, 102 (77\%) had T4b primary tumors. Additionally, 41 (31\%) patients had supraclavicular lymph node metastasis, and 31 (23\%) had lymph node metastasis invading the neighboring organs.

Patient flow is outlined in Figure 1. Among the enrolled patients, 31 (23\%) achieved CR, whereas 102 (77\%) fell into RD. Among the 31 patients in the CR group, 5 experienced recurrence, while one underwent salvage surgery and achieved curative resection. Among the 102 patients in the RD group, 11 underwent salvage surgery, and 6 of them achieved curative resection.

\section{Pretherapeutic predictive factors for residual disease}

A comparison of the clinicopathological factors between the groups [Table 1] showed that the RD group included more patients with a higher serum SCC-Ag levels $(P=0.048)$ and there may be a higher incidence of the supracarinal tumor than the $\mathrm{CR}$ group $(P=0.059)$. Multivariate analysis showed that a supracarinal tumor $(\mathrm{OR}=3.21 ; 95 \% \mathrm{CI}: 1.24-8.33 ; P=0.016)$, increased pretherapeutic serum SCC-Ag level $(>1.6 \mathrm{ng} / \mathrm{mL})$ $(\mathrm{OR}=2.86 ; 95 \% \mathrm{CI}: 1.19-7.14 ; P=0.018)$, and non-T4b tumors (metastatic node invasion; $\mathrm{OR}=3.19 ; 95 \% \mathrm{CI}$ : 1.01-10.1; $P=0.048$ ) were independent predictors of RD [Table 2].

\section{Patient survival and pretherapeutic prognostic factors}

The median OS of all patients was 14.9 (95\%CI: 11.8-17.9) months and was significantly better in the CR group than in the RD group (89.9 months vs. 10.7 months, respectively; $\mathrm{HR}=0.096 ; 95 \% \mathrm{CI}: 0.05-0.19 ; P<$ 0.001; Figure 2).

Multivariate analysis showed that increased pretherapeutic serum SCC-Ag levels $(>1.6 \mathrm{ng} / \mathrm{mL})(\mathrm{OR}=1.62$; 95\%CI: 1.08-2.43; $P=0.02$ ) was an independent predictor of poor patient survival [Table 3]. Patients with higher pretherapeutic SCC-Ag levels had significantly worse OS compared to those with lower pretherapeutic SCC-Ag levels (12.6 months vs. 17.9 months, respectively; HR = 1.68; 95\%CI: 1.12-2.51; $P=$ 0.012; Figure 3).

\section{DISCUSSION}

The current retrospective study evaluated treatment outcomes in a relatively large number of patients receiving dCRT for LU-ESCC, which is relevant to actual clinical practice. Importantly, our results showed that pretherapeutic serum SCC-Ag level was an independent predictor of $\mathrm{RD}$, as well as poor patient survival, following dCRT. To the best of our knowledge, this has been the first study to show the clinical significance of pretherapeutic SCC-Ag level in patients receiving dCRT for LU-ESCC.

Regarding the efficacy of dCRT for LU-ESCC, Ohtsu et al. ${ }^{[6]}$ had previously reported that $25 \%$ of patients with T4 ESCC achieved CR following dCRT. Meanwhile, the present study showed that dCRT for LU-ESCC promoted a CR rate of $23 \%$ - a finding consistent with that presented in a previous Japanese nationwide study wherein a CR rate of $23.1 \%$ was achieved in patients with $\mathrm{T} 4 \mathrm{ESCC}^{[5]}$.

However, the absence of a distinct definition for the diagnosis of CR after dCRT has remained a problem. Fibrotic scars could increase the difficulty of accurately diagnosing the extent and depth of the tumor, as well as detecting cancer cells. Occasionally, CT findings show the presence of significant esophageal wall thickening even when no cancer cells are present. Moreover, although previous studies have suggested that 
Table 1. Patient characteristics

\begin{tabular}{|c|c|c|c|c|c|}
\hline \multicolumn{2}{|c|}{ Variables } & \multirow{2}{*}{$\begin{array}{l}\text { Total }(n=133) \\
63(38-80)\end{array}$} & \multirow{2}{*}{$\begin{array}{l}\text { CR }(\boldsymbol{n}=\mathbf{3 1}) \\
63(47-73)\end{array}$} & \multirow{2}{*}{$\begin{array}{l}\text { RD }(\boldsymbol{n}=102) \\
64(38-80)\end{array}$} & \multirow{2}{*}{$\begin{array}{l}\text { P value } \\
0.56\end{array}$} \\
\hline Age (years) & & & & & \\
\hline \multirow[t]{2}{*}{ Sex } & Female & $30(23 \%)$ & $8(26 \%)$ & $22(22 \%)$ & 0.63 \\
\hline & Male & $103(77 \%)$ & $23(74 \%)$ & $80(78 \%)$ & \\
\hline \multirow[t]{2}{*}{ Main tumor location } & Supracarina & $56(42 \%)$ & $8(26 \%)$ & $48(47 \%)$ & 0.059 \\
\hline & Infracarina & $77(58 \%)$ & $23(74 \%)$ & $54(50 \%)$ & \\
\hline \multirow[t]{2}{*}{ Serum SCC-Ag level } & $\leq 1.6 \mathrm{mg} / \mathrm{mL}$ & $63(47 \%)$ & $20(65 \%)$ & $43(42 \%)$ & 0.048 \\
\hline & $>1.6 \mathrm{mg} / \mathrm{mL}$ & $70(53 \%)$ & $11(35 \%)$ & $59(58 \%)$ & \\
\hline \multirow[t]{3}{*}{ GPS } & 0 & $79(59 \%)$ & $21(68 \%)$ & $58(57 \%)$ & 0.50 \\
\hline & 1 & $39(29 \%)$ & $8(26 \%)$ & $31(30 \%)$ & \\
\hline & 2 & $15(11 \%)$ & $2(6 \%)$ & $13(13 \%)$ & \\
\hline \multirow[t]{2}{*}{ cT category } & Non-T4b & $31(23 \%)$ & $5(16 \%)$ & $26(25 \%)$ & 0.34 \\
\hline & $\mathrm{T} 4 \mathrm{~b}$ & $102(77 \%)$ & $26(84 \%)$ & $76(75 \%)$ & \\
\hline \multirow[t]{3}{*}{ cN category } & NO & $4(3 \%)$ & $1(3 \%)$ & $3(3 \%)$ & 0.68 \\
\hline & N1 & $86(65 \%)$ & $22(71 \%)$ & $64(63 \%)$ & \\
\hline & $\mathrm{N} 2-3$ & $43(32 \%)$ & $8(26 \%)$ & $35(34 \%)$ & \\
\hline cM category & MOM1 & $\begin{array}{l}92(69 \%) \\
41(31 \%)\end{array}$ & $\begin{array}{l}68(67 \%) \\
34(33 \%)\end{array}$ & $\begin{array}{l}24(77 \%) \\
7(23 \%)\end{array}$ & 0.37 \\
\hline
\end{tabular}

All data are presented as medians (range) or numbers (\%). CR: Complete response; GPS: Glasgow prognostic score; RC: residual disease; SCCAg: squamous cell carcinoma antigen.

Table 2. Multivariate analysis for predictive factors of residual disease

\begin{tabular}{lllll}
\hline & Variables & OR & $\mathbf{9 5 \% C l}$ & P value \\
\hline Tumor location & Infracarina (Reference) & - & - & - \\
\multirow{2}{*}{ Serum SCC-Ag level } & Supracarina & 3.21 & $1.24-8.33$ & 0.016 \\
& $\leq 1.6 \mathrm{mg} / \mathrm{mL}$ (Reference) & - & - & - \\
CT category & $>1.6 \mathrm{mg} / \mathrm{mL}$ & 2.86 & $1.19-7.14$ & 0.018 \\
& T4b (Reference) & - & - & - \\
& Non-T4b & 3.19 & $1.01-10.1$ & 0.048 \\
\hline
\end{tabular}

RD: Residual disease; OR: odds ratio; Cl: confidence interval; SCC-Ag: squamous cell carcinoma antigen.

Table 3. Multivariate analysis for predictive factors of overall survival

\begin{tabular}{lllll}
\hline & Variables & HR & $\mathbf{9 5 \%} \mathbf{C l}$ & P value \\
\hline Tumor location & Infracarina (Reference) & - & - & - \\
& Supracarina & 1.52 & $1.00-2.32$ & 0.051 \\
Serum SCC-Ag level & $\leq 1.6 \mathrm{mg} / \mathrm{mL}$ (Reference) & - & - & - \\
& $>1.6 \mathrm{mg} / \mathrm{mL}$ & 1.62 & $1.08-2.43$ & 0.02 \\
CT category & T4b (Reference) & - & - & - \\
& Non-T4b & 1.26 & $0.79-2.00$ & 0.29 \\
\hline
\end{tabular}

HR: Hazard ratio; Cl: confidence interval; SCC-Ag: squamous cell carcinoma antigen.

endoscopic biopsy examination after dCRT could predict therapeutic responses, majority of the cases with negative biopsy results displayed residual tumor cells in their surgical specimen. Therefore, given the occasional difficulty in estimating $\mathrm{RD}$ or $\mathrm{CR}$ after $\mathrm{dCRT}$, the present study also considered the duration for which no cancer treatment had been provided. Nonetheless, more well-established evaluation methods for CR should be considered. 


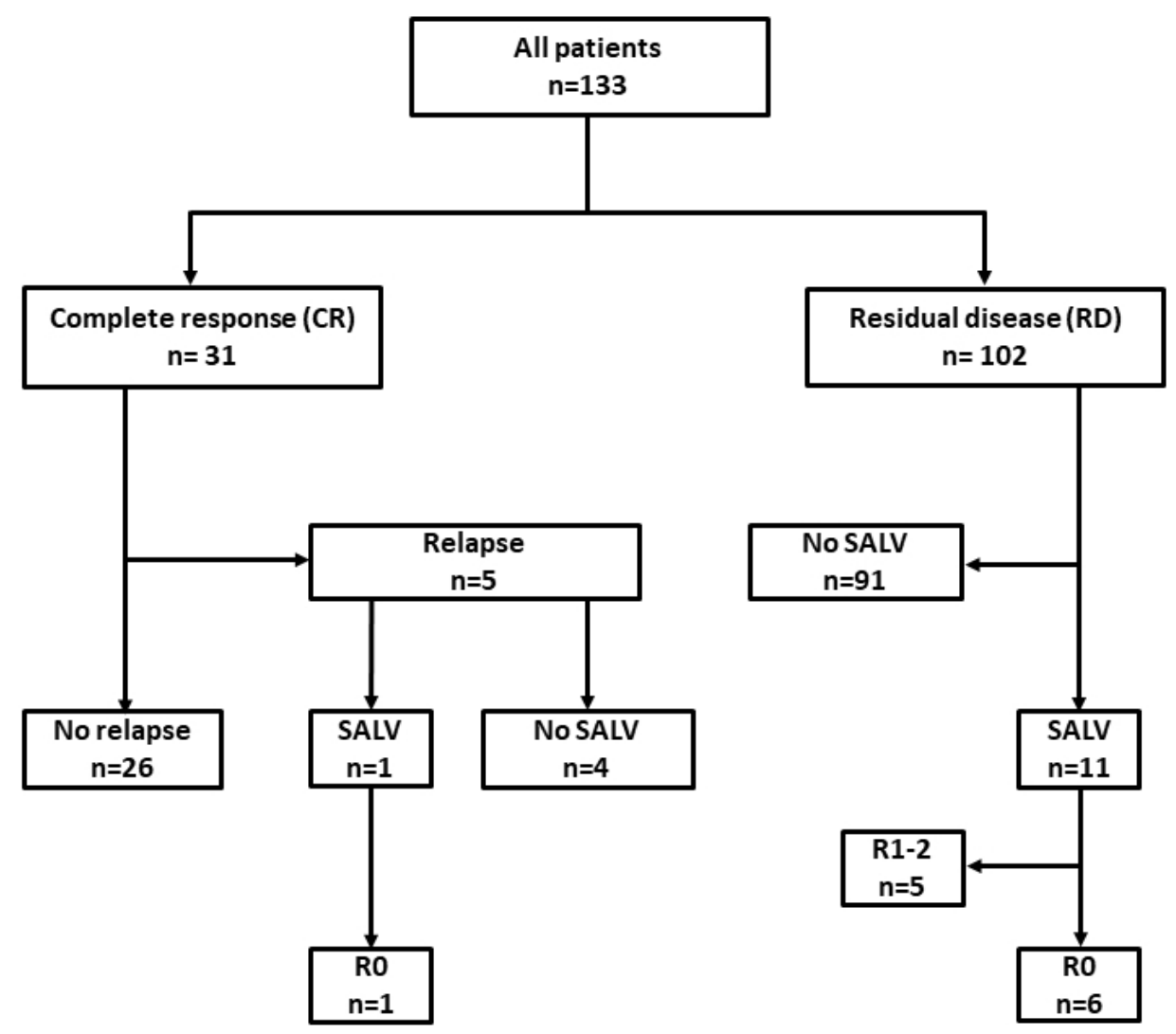

Figure 1. Flow diagram of patient selection and analysis. SALV: Salvage surgery.

Regarding predictive factors for patient survival, Sugawara et al ${ }^{[10]}$ identified elevated pretherapeutic C-reactive protein levels as a poor predictor in 73 patients with LU-ESCC. Although the present study did not find the Glasgow prognostic score as a significant factor for survival, increased pretherapeutic serum SCC-Ag levels (>1.6 ng/mL) had been identified as a significant predictor of poor survival, as well as an independent predictor of $\mathrm{RD}$.

Several reports have suggested the clinical significance of serum SCC-Ag levels in patients with ESCC. Accordingly, studies have shown that elevated levels of pretherapeutic serum SCC-Ag were associated with advanced tumor stage, poor response to neoadjuvant treatment, inability for curative resection, and poor prognosis ${ }^{[12,13,16,17]}$. The results presented herein also demonstrated that pretherapeutic serum SCC-Ag levels were predictive of sensitivity to dCRT given their ability to predict RD in LU-ESCC. Previous studies have suggested that SCC-Ag can protect cancer cells from apoptosis induced by irradiation, medicine, cytokine, and effector cells ${ }^{[18-21]}$. Although the mechanisms remain unclear, the biological function of SCC-Ag or tumor burden could affect the sensitivity to dCRT in ESCC.

Additionally, the current study confirmed that supracarinal tumors and metastatic node invasion were independent factors for RD. The supracarinal esophagus is surrounded by several vital organs, including the trachea and aortic arch, within a narrow space. Therefore, esophageal cancer in this location frequently invades such unresectable organs. Presumably, this anatomical characteristic could make supracarinal tumors a risk factor for RD. Regarding metastatic node invasion, several reports have suggested that extracapsular lymph node invasion could have a negative prognostic impact in patients with ESCC ${ }^{[22,23]}$, confirming that ESCC with extracapsular lymph node invasion has a highly aggressive biological behavior, 


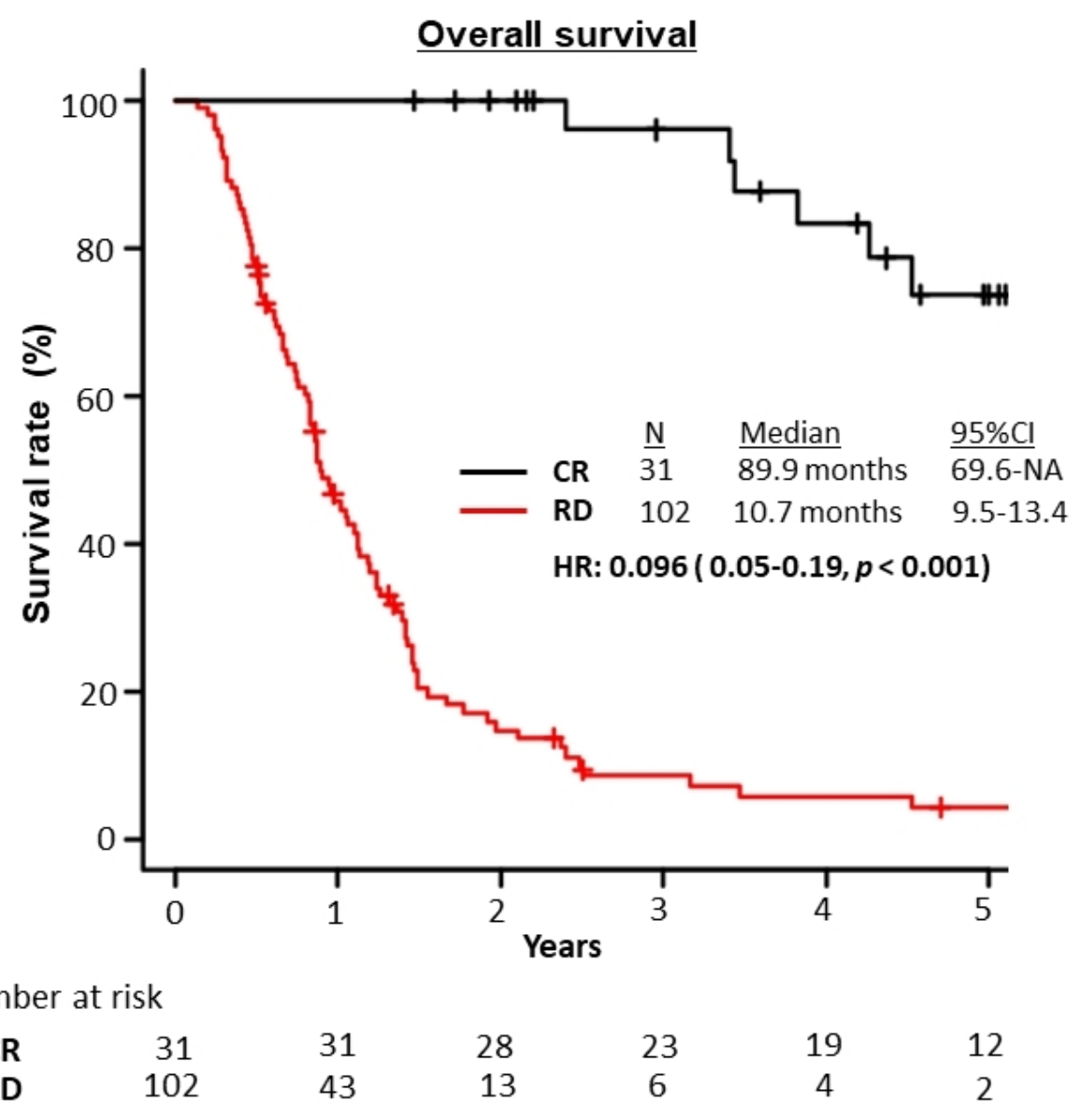

Figure 2. Overall survival of the CR and RD groups. CR: Complete response; RD: residual disease.

which could explain why metastatic node invasion could be a significant factor for RD.

Our data demonstrated that dCRT with FP plus irradiation with 60 Gy had insufficient efficacy for patients with LU-ESCC at high risk for RD. Therefore, alternative strategies or regimens with more vigorous antitumor activities are required to improve outcomes. Yokota $e t$ al ${ }^{[24]}$ reported feasible and promising results for chemoselection with induction docetaxel plus FP (DFP) and subsequent conversion surgery for LU-ESCC. Following such results, a randomized phase 3 study on induction DFP vs. dCRT for LU-ESCC and borderline resectable ESCC is currently ongoing in $\operatorname{Japan}^{[25]}$, and the results are awaited. Meanwhile, DFP plus irradiation (DFP-RT) is also expected to improve outcomes, with a CR rate of $52.4 \%$ in patients with LU-ESCC or M1 lymph node metastasis ${ }^{[26]}$. Moreover, a recent comparative study involving advanced ESCC showed that rates of OS and CR after DFP-RT were improved compared to dCRT with $\mathrm{FP}^{[27]}$. Despite being associated with higher rates of leukopenia, DFP-RT could be a promising treatment regimen for LU-ESCC with proper myelotoxicity management.

The current study has some limitations worth considering. First, given that this was a single-center, retrospective observational study, selection bias was inevitable. Second, although LU-ESCC diagnosis and associated decisions were determined by a multidisciplinary tumor board, no consensus on the diagnosis of LU-ESCC had been established. Indeed, inter-evaluator variations in diagnosis of locally advanced esophageal cancer have been reported ${ }^{[2,29]}$. Third, as mentioned previously, no distinct criteria for CR after 


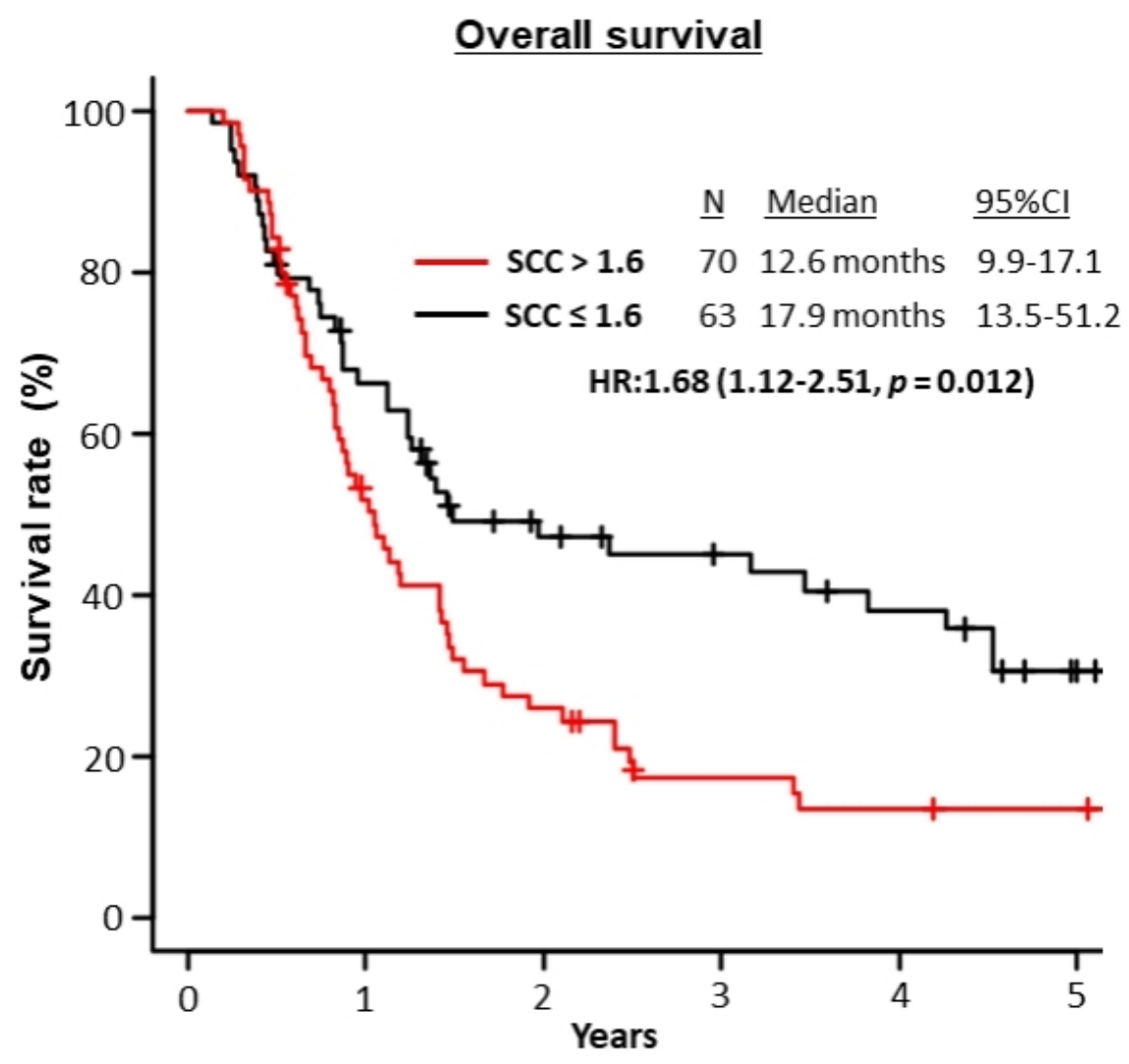

Number at risk

$\begin{array}{llllccl}\text { SCC > 1.6 } & 70 & 34 & 17 & 9 & 7 & 6 \\ \text { SCC } \leq 1.6 & 63 & 40 & 24 & 20 & 16 & 8\end{array}$

Figure 3. Overall survival of the study population stratified by serum SCC antigen levels (> $1.6 \mathrm{ng} / \mathrm{mL}$ ). SCC: Squamous cell carcinoma.

dCRT had been established. Therefore, further prospective studies, including higher numbers of patients with a more accurate clinical diagnosis and more well-established evaluation methods after dCRT are required.

In conclusion, the present study found that $23 \%$ of the patients with LU-ESCC achieved CR following dCRT with FP plus irradiation with 60 Gy. Moreover, our results showed that increased pretherapeutic serum SCC-Ag levels were predictive of treatment failure and poor survival. Alternative strategies consisting of multimodality treatment modalities are required to improve the outcomes of patients with an increased level of serum SCC-Ag.

\section{DECLARATIONS}

\section{Authors' contributions}

Conception and design: Suzuki T, Okamura A, Watanabe M, Asari T, Nakayama I, Ogura M, Ooki A, Takahari D, Yamaguchi K, Chin K

Acquisition, analysis, and interpretation of data: Suzuki T, Okamura A, Asari T

Drafting the article: Suzuki T, Okamura A, Watanabe M, Chin K

Revising it critically for important intellectual content: Suzuki T, Okamura A, Watanabe M, Asari T, Nakayama I, Ogura M, Ooki A, Takahari D, Yamaguchi K, Chin K 
Final approval of the version to be published: Suzuki T, Okamura A, Watanabe M, Asari T, Nakayama I, Ogura M, Ooki A, Takahari D, Yamaguchi K, Chin K

\section{Availability of data and materials \\ Not applicable.}

\section{Financial support and sponsorship}

None.

\section{Conflicts of interest}

All authors declared that there are no conflicts of interest.

\section{Ethical approval and consent to participate}

All procedures and analysis were performed in accordance with the approval of our institutional review board and the Helsinki Declaration of 1964. Consent from participants was confirmed with opt-out agreement.

\section{Consent for publication}

All the authors gave definitive approval to publication.

\section{Copyright}

(c) The Author(s) 2022.

\section{REFERENCES}

1. GLOBOCAN database. Available from: http://gco.iarc.fr/. [Last accessed on 19 Jan 2022].

2. Sasaki Y, Tamura M, Koyama R, Nakagaki T, Adachi Y, Tokino T. Genomic characterization of esophageal squamous cell carcinoma: Insights from next-generation sequencing. World J Gastroenterol 2016;22:2284-93. DOI PubMed PMC

3. Seto Y, Chin K, Gomi K, et al. Treatment of thoracic esophageal carcinoma invading adjacent structures. Cancer Sci 2007;98:937-42. DOI PubMed

4. Tachimori Y, Ozawa S, Numasaki H, et al; Registration Committee for Esophageal Cancer of the Japan Esophageal Society. Comprehensive registry of esophageal cancer in Japan, 2012. Esophagus 2019;16:221-45. DOI PubMed PMC

5. Toh Y, Numasaki H, Tachimori Y, et al. Current status of radiotherapy for patients with thoracic esophageal cancer in Japan, based on the Comprehensive Registry of Esophageal Cancer in Japan from 2009 to 2011 by the Japan Esophageal Society. Esophagus 2020;17:25-32. DOI PubMed

6. Ohtsu A, Boku N, Muro K, et al. Definitive chemoradiotherapy for T4 and/or M1 lymph node squamous cell carcinoma of the esophagus. J Clin Oncol 1999;17:2915-21. DOI PubMed

7. Kitagawa Y, Uno T, Oyama T, et al. Esophageal cancer practice guidelines 2017 edited by the Japan esophageal society: part 2. Esophagus 2019;16:25-43. DOI PubMed PMC

8. Ishida K, Ando N, Yamamoto S, Ide H, Shinoda M. Phase II study of cisplatin and 5-fluorouracil with concurrent radiotherapy in advanced squamous cell carcinoma of the esophagus: a Japan Esophageal Oncology Group (JEOG)/Japan Clinical Oncology Group trial (JCOG9516). Jpn J Clin Oncol 2004;34:615-9. DOI PubMed

9. Shinoda M, Ando N, Kato K, et al; Japan Clinical Oncology Group. Randomized study of low-dose versus standard-dose chemoradiotherapy for unresectable esophageal squamous cell carcinoma (JCOG0303). Cancer Sci 2015;106:407-12. DOI PubMed PMC

10. Sugawara K, Yagi K, Okumura Y, et al. Long-term outcomes of multimodal therapy combining definitive chemoradiotherapy and salvage surgery for T4 esophageal squamous cell carcinoma. Int J Clin Oncol 2020;25:552-60. DOI PubMed

11. Okamura A, Matsuda S, Mayanagi S, et al. Clinical significance of pretherapeutic serum squamous cell carcinoma antigen level in patients with neoadjuvant chemotherapy for esophageal squamous cell carcinoma. Ann Surg Oncol 2021;28:1209-16. DOI PubMed

12. Suzuki T, Okamura A, Watanabe M, et al. Neoadjuvant chemoradiotherapy with cisplatin plus fluorouracil for borderline resectable esophageal squamous cell carcinoma. Ann Surg Oncol 2020;27:1510-7. DOI PubMed

13. McMillan DC, Forrest LM, O'Gorman P, Angerson WJ, McArdle CS. Performance status of male and female advanced cancer patients is independently predicted by mid-upper arm circumference measurement. Nutr Cancer 2002;42:191-3. DOI PubMed

14. Brierley JD, Gospodarowicz MK, Wittekind C. TNM classification of malignant tumors. International union against cancer. 8th ed. Oxford: Wiley; 2017.

15. Kanda Y. Investigation of the freely available easy-to-use software 'EZR' for medical statistics. Bone Marrow Transplant 2013;48:4528. DOI PubMed PMC 
16. Shimada H, Nabeya Y, Okazumi S, et al. Prediction of survival with squamous cell carcinoma antigen in patients with resectable esophageal squamous cell carcinoma. Surgery 2003;133:486-94. DOI PubMed PMC

17. Okamura A, Watanabe M, Mine S, et al. Failure of neoadjuvant chemotherapy for resectable esophageal squamous cell carcinoma. Dis Esophagus 2017;30:1-8. DOI PubMed

18. Suminami Y, Nagashima S, Vujanovic NL, Hirabayashi K, Kato H, Whiteside TL. Inhibition of apoptosis in human tumour cells by the tumour-associated serpin, SCC antigen-1. Br J Cancer 2000;82:981-9. DOI PubMed PMC

19. Murakami A, Suminami Y, Hirakawa H, Nawata S, Numa F, Kato H. Squamous cell carcinoma antigen suppresses radiation-induced cell death. Br J Cancer 2001;84:851-8. DOI PubMed PMC

20. Luke CJ, Pak SC, Askew YS, et al. An intracellular serpin regulates necrosis by inhibiting the induction and sequelae of lysosomal injury. Cell 2007;130:1108-19. DOI PubMed PMC

21. Markovina S, Wang S, Henke LE, et al. Serum squamous cell carcinoma antigen as an early indicator of response during therapy of cervical cancer. Br J Cancer 2018;118:72-8. DOI PubMed PMC

22. Sakai M, Suzuki S, Sano A, et al. Significance of lymph node capsular invasion in esophageal squamous cell carcinoma. Ann Surg Oncol 2012;19:1911-7. DOI PubMed

23. Lagarde SM, Navidi M, Gisbertz SS, et al. Prognostic impact of extracapsular lymph node involvement after neoadjuvant therapy and oesophagectomy. Br J Surg 2016;103:1658-64. DOI PubMed

24. Yokota T, Kato K, Hamamoto Y, et al. A 3-year overall survival update from a phase 2 study of chemoselection with DCF and subsequent conversion surgery for locally advanced unresectable esophageal cancer. Ann Surg Oncol 2020;27:460-7. DOI PubMed

25. Terada M, Hara H, Daiko H, et al. Phase III study of tri-modality combination therapy with induction docetaxel plus cisplatin and 5fluorouracil versus definitive chemoradiotherapy for locally advanced unresectable squamous-cell carcinoma of the thoracic esophagus (JCOG1510: TRIANgLE). Jpn J Clin Oncol 2019;49:1055-60. DOI PubMed

26. Higuchi K, Komori S, Tanabe S, et al; Kitasato Digestive Disease and Oncology Group. Definitive chemoradiation therapy with docetaxel, cisplatin, and 5-fluorouracil (DCF-R) in advanced esophageal cancer: a phase 2 trial (KDOG 0501-P2). Int J Radiat Oncol Biol Phys 2014;89:872-9. DOI PubMed

27. Tamaki Y, Hieda Y, Nakajima M, et al. Concurrent chemoradiotherapy with docetaxel, cisplatin, and 5-fluorouracil improves survival of patients with advanced esophageal cancer compared with conventional concurrent chemoradiotherapy with cisplatin and 5fluorouracil. J Cancer 2018;9:2765-72. DOI PubMed PMC

28. Hamamoto Y, Nojima M, Aoki Y, et al. Inter-evaluator heterogeneity of clinical diagnosis for locally advanced esophageal squamous cell carcinoma. Esophagus 2017;14:324-32. DOI PubMed PMC

29. Yokota T, Yasuda T, Kato H, et al. Concordance of clinical diagnosis of T classification among physicians for locally advanced unresectable thoracic esophageal cancer. Int J Clin Oncol 2018;23:73-80. DOI PubMed 